\title{
What is the effect of a shoulder-strengthening program to prevent shoulder pain among junior female team handball players?
}

This article was published in the following Dove Press journal:

Open Access Journal of Sports Medicine

30 March 2017

Number of times this article has been viewed

\section{Maria Sommervold \\ Håvard $\varnothing$ sterås}

Department of Neuromedicine and Movement Science, Norwegian University of Science and Technology (NTNU), Trondheim, Norway
Correspondence: Håvard Østerås Norwegian University of Science and Technology, Department of Neuromedicine and Movement Science, Trondheim, Norway

Tel +47 73559305

Email havard.osteras@ntnu.no
Background: Excessively high stresses are applied to the shoulder joint of handball players, mainly caused by overhead throwing. Shoulder pain is a significant problem among junior female team handball players and both male and female top-level team handball players in Norway. Method: A randomized selection was performed among the best female junior teams ( $\mathrm{J} 16)$ in the Trøndelag region of Norway in the 2014-2015 season. Three teams were randomized to the intervention group and three teams to the control group. Players in the intervention group $(n=53)$ participated in a seven-month, three-times-a-week shoulder-muscle strength-training program, while those in the control group $(n=53)$ participated in a comparable handball training, but did not conduct any specific strength training during the season.

Results: A strength-training program had no effect on the prevention of shoulder pain. Overall, the players reported shoulder pain, but graded the pain low on visual analog scale (VAS). Both the intervention group and the control group reported pain under 1 on VAS at baseline and posttest, and there was no significant difference within or between the groups when it came to the intensity of pain reported on VAS. A significant difference $(p<0.048)$ was found between the groups on the sport-specific part of the quick-Disability of the Arm, Shoulder and Hand (DASH) form, but it did not fulfill the minimal demand to change and the players scored it low, something that indicates little functional problems when it comes to team handball. The intervention group was significantly stronger $(p<0.008)$ on the push-ups test compared to the control group on the posttest. The intervention group increased the number of push-ups from 3.1 to 6.4, while the control group went from 2.3 to 3.6. Aside from this, there were no significant differences in between the groups. Conclusion: A shoulder-strengthening program had no effect on the prevention of shoulder pain among junior female team handball players.

Keywords: shoulder, strengthening, prevention, handball, randomized.

\section{Introduction}

European team handball is among the most popular team sports in Norway and Scandinavia. ${ }^{1}$ Around 100,000 players are registered in the Norwegian Handball Federation, and two-third of the players are under the age of $17 .{ }^{2}$ European team handball combines aspects of both basketball, American football and baseball. ${ }^{3}$ The shoulder joint of handball players is applied to excessively high stress, mainly caused by overhead throwing. This is comparable to the stress found among pitchers in baseball. ${ }^{4}$ The speed of a handball throw can reach up to $130 \mathrm{~km} / \mathrm{h}$, and a handball player can perform at least 48,000 throwing movements during a single season. ${ }^{5}$ In addition to the throwing movements, handball players are also tackled, ${ }^{6}$ which increase the potential for shoulder injuries. ${ }^{3}$ 
The throwing movement demands a complex interaction between the lower extremity, the trunk and the upper extremity. This interaction is known as the kinetic chain. The function of the chain is to transform the force from the ground, through the under extremity, pelvis, trunk, shoulder joint, elbow joint, wrist to the terminal segment, which is the ball. ${ }^{7,8}$ The core stability is crucial for an effective biomechanical function to maximize the force transformation and to minimize the joint load. ${ }^{9}$

Acute and traumatic injuries in the throwing shoulder among handball players do occur, but most of the injuries are due to overuse of the shoulder. ${ }^{10}$ The shoulder joint of overhead throwing athletes is exposed to an enormous stress. The throw arm must have a high degree of mobility combined with joint stability. The balance between mobility and stability is often disturbed, which again can lead to injuries. ${ }^{11}$ The repetitive tackles and throwing movements will eventually lead to micro-traumas in the ligament and capsule structures in the anterior aspects of the shoulder. The load can eventually exceed the tolerance, which again will lead to the stretching of the capsule and ligament structures. ${ }^{12,13}$ To begin with, this can be compensated with increased muscle activity in the dynamical stabilization muscles. Continuous activity will eventually lead to the exhaustion of the rotator cuff, which no longer can stabilize the humeral head in the cavitas glenoid. ${ }^{14}$

There existed no scientific consensus nor best practice on how to best prevent shoulder complaints in team handball when this study was planned. $.^{15}-^{18}$ The aim of this study was to investigate whether a strength-training program performed three times a week during a season could reduce shoulder complaints among 16-year-old female team handball players. The hypothesis was that such strength-training programs could reduce the prevalence of shoulder complaints among junior female team handball players.

\section{Materials and methods Subjects}

A randomized selection was performed among the best female junior teams (J 16) in the Trøndelag region of Norway in the 2014-/2015 season. Each of the team names was written on a piece of paper, and then was put in a sealed envelope before a randomized selection was performed by a draw. Three teams were randomized to the intervention group and three teams to the control group. Players in the intervention group $(n=53)$ participated in a seven-month, three-times-a-week shouldermuscle strength-training program, while those in the control group $(\mathrm{n}=53)$ participated in a comparable handball training but did not conduct any specific strength training during the season. Exclusion criterion included previously undergone shoulder surgery.

\section{Data collection}

The participation in this study was voluntary. Players eligible for inclusion received both written and oral information about the study. All players who consented to participation filled in a written consent form, and performed baseline and posttest testing in the 2014-2015 season. A written consent for publication of the images was also provided by the people performing the exercises in the images (Figure 1A-F). Data were collected using different questionnaires, and all players filled in two questionnaires at baseline and posttest, in addition to three physical tests. The questionnaires were anonymized and coded, so that subject anonymity was assured. The study was approved by the Regional Ethics Committee, Mid-Norway, and the study was registered on Clinicaltrials. gov (ID: NCT02361395).

\section{Questionnaires}

Functional disability was measured using the Quick-Disability of the Arm, Shoulder and Hand (Quick-DASH) questionnaire. The Norwegian version of DASH has shown to be both valid and reliable outcome for patients with impingement symptoms in the shoulder, ${ }^{19}$ a condition that often develops secondary among throwers. ${ }^{14}$ An easier version of the questionnaire is also developed and is known as the Quick-DASH. The Quick-DASH is an 11-item questionnaire that addresses symptoms and physical function in people with disorders involving the upper limb. ${ }^{20}$ The Quick-DASH is preferred since it gives the same information, except for that it is shorter and has acceptable values for both reliability and validity. ${ }^{20,21}$ Nine of 11 questions must be answered to calculate a score between 0 (that indicates no functional problems) and 100 (that indicates the highest level of functional problems). ${ }^{20,21}$

Pain intensity was measured on a visual analog scale (VAS), a scale that is sensitive for measuring pain ${ }^{22}$ and valid for measuring pain intensity. ${ }^{23}$ The scale used was the typical $100 \mathrm{~mm}$ horizontal line, with $0 \mathrm{~mm}$ indicating "no pain" and $100 \mathrm{~mm}$ indicating "unbearable pain."22 Everything above $0 \mathrm{~mm}$ was considered as pain in this study.

All players were asked to grade their pain in the throwing shoulder monthly. At the end of every month, they were asked to grade the shoulder pain: "now," "last week" and "last month." In the beginning of the season, the coaches got pre-coded VAS schemes for all the players. At the end of every month, the coaches got a reminder on text message to have the players fill in the VAS scheme. The coaches then collected the schemes and sent them to us in a prepaid envelope. 

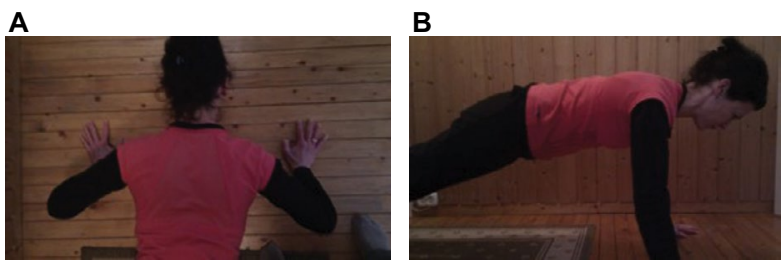

D

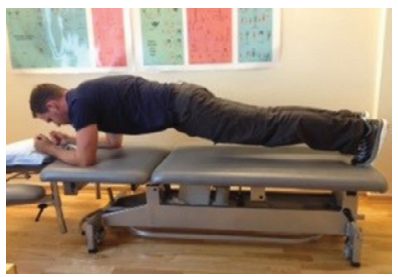

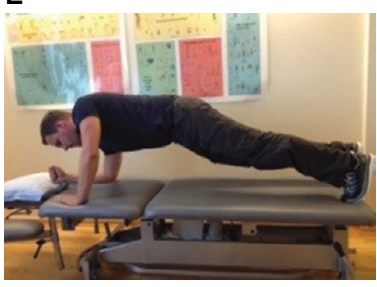

C
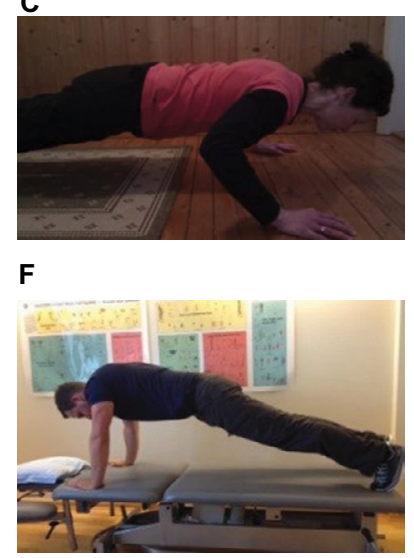

Figure I (A, B and C) Push-ups. (D) Push exercise starting position. (E) Push exercise mid-position. (F) Push exercise end position.

\section{Baseline and posttest testing}

The players performed three physical tests at baseline and posttest. They were tested using a maximal repetition test of push-ups (Figure 1), maximal throwing distance and strength of the internal- and external rotators of the throwing shoulder measured with a handheld dynamometer. A MicroFET 2 handheld dynamometer (Hoggan Health Industries, Salt Lake, UT, USA) was used to objectively measure the strength. A pilot study to test the inner reliability was not performed, since the intrarater validity and reliability when using a handheld dynamometer are well established in the litterature. ${ }^{24-26}$

\section{Intervention}

As a prolonged part of the warm-up period of training, the players in the intervention group performed two exercises three times a week throughout the season (seven months). The exercises were performed with $3 \times 12$ repetitions of high fatigue:

1. Push-ups with 1 minute break between the series, explosive performance, $0^{\circ}-90^{\circ}$ flexion of the elbows, elbows abducted $45^{\circ}$ from the thorax.

2. Moving the body from elbow standing to hand standing with extended elbows and then down to elbow standing again. The purpose of the exercise was to have the athletes develop force in an instable setting.

The exercises were introduced to the players in the intervention group in the beginning of the season, and all players got feedback on the how they performed them. They also got a written explanation of the exercises, in addition to pictures of them with different variances regarding progression. A month after the first visit, the teams in the intervention group were visited again for another review of the exercises. The coaches had access to the authors throughout the season.

\section{Statistical analysis}

Data were descriptively analyzed by comparing between preand post-season tests. Statistical analyses were conducted using a Student's $t$-test in SPSS 23 with $p<0.05$ as statistical significance criterion. An unpaired (independent) Student's $t$-test was used to compare the mean between the two groups, while repeated measures analysis of variance (ANOVA) was used to find any difference between the groups on VAS over time. ${ }^{27}$ Pain was the main outcome in the study, and the minimal clinical relevant difference on VAS was 2 . Statistical power was set at $0.8 .{ }^{28}$

Based on previous studies on epidemiology of shoulder pain among handball players, ${ }^{29,30}$ the expected mean and standard deviation for the VAS were used. The effect size was calculated based on this. Pain was the primary outcome in this study, and the minimal detectable value on VAS was set to 2. Test strength (power) was set to 0.8 and the level of significance to $5 \% .{ }^{28}$ Based on this, it was estimated that 70 people had to be included in the study.

Expected dropout varies, and it is operated with numbers from $10 \%$ to $30 \%$ depending on the type of intervention. ${ }^{6,31,32}$ An expected dropout of $30 \%$ was calculated in this study, so that at least 91 players were to be included. Since two teams in each group were not enough to include the number of players needed, three teams were included in both the intervention group and the control group. To avoid excluding some players in each team, a total of 106 players were included in the study.

\section{Results}

\section{Flow of the players throughout the study}

A total of 106 players agreed to participate in the study at baseline. The number that completed the questionnaires was tested and included in each analysis is shown in Figure 2. 


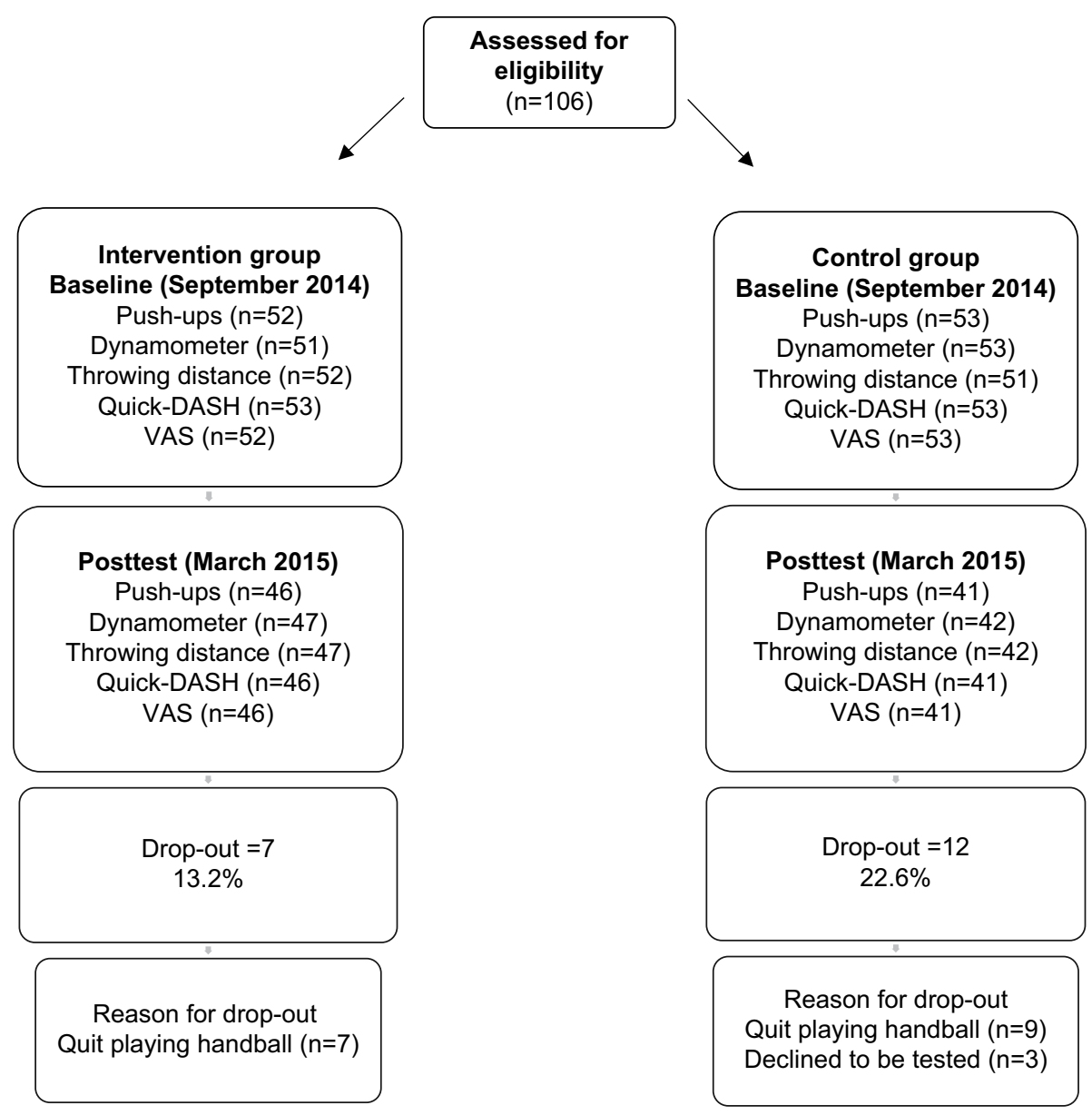

Figure 2 Flow of the players throughout the study.

Abbreviations: DASH, Disability of the Arm, Shoulder and Hand; VAS, visual analog scale.

\section{Shoulder pain}

The players graded their pain in the throwing shoulder on VAS at baseline and posttest, in addition to once a month throughout the season. They graded the pain: "today," "last week" and "last month."

Table 1 shows the mean pain intensity "today" on the VAS throughout the season, in addition to standard deviation, minimal- and maximal value measured on VAS, and the $p$-value.

A presentation of the players who reported pain and a grading of their pain intensity is shown in Table 2. All values above 0 on VAS was considered as pain.

\section{Quick-DASH}

As presented in Table 3, there was no significant difference in between the two groups regarding the quick-DASH score. A significant difference was found between the score on the sport-specific part of the form (quick-DASH-sport) on posttest between the groups.

Table 3 shows the score on quick-DASH and the sportspecific part of the form, quick-DASH-sport, in addition to the mean, standard deviation and $p$-value.

\section{Functional tests}

A significant difference was found when it came to the number of push-ups between the intervention group and the control group. Except for that, no significant difference between the groups was found when it came to the functional tests as presented in Table 4.

A presentation of the three physical tests at baseline and posttest, in addition to the mean, standard deviation and $p$-value, is shown in Table 4.

\section{Response rate and compliance}

Shoulder pain in the throwing shoulder "now," "last week" and "last month" was reported every month throughout the season. The response rate varied as shown in Table 5 (for graphical representation, see Figure 3). All the teams in the intervention group were asked to fill in a compliance form throughout the season, but none of the teams filled it. Therefore, we had no data of team compliance in this study.

\section{Discussion}

The aim of this study was to investigate whether a strengthtraining program performed three times a week during a season 
Table I Mean pain intensity "today" on VAS throughout the season, SD, minimal and maximal values measured on VAS and $p$-value

\begin{tabular}{|c|c|c|c|c|c|c|c|}
\hline Month & Group & $\mathbf{N}$ & Mean & SD & $\begin{array}{l}\text { Minimum } \\
\text { value VAS }\end{array}$ & $\begin{array}{l}\text { Maximum } \\
\text { value VAS }\end{array}$ & $p$-value \\
\hline \multirow[t]{2}{*}{ September } & Intervention group & 52 & 0.8 & 1.3 & 0 & 6 & 0.608 \\
\hline & Control group & 53 & 0.7 & 1.6 & 0 & 8 & \\
\hline \multirow[t]{2}{*}{ October } & Intervention group & 36 & 0.4 & 0.9 & 0 & 4 & 0.874 \\
\hline & Control group & 51 & 0.4 & 0.9 & 0 & 4 & \\
\hline \multirow[t]{2}{*}{ November } & Intervention group & 44 & 0.8 & 2 & 0 & 10 & 0.266 \\
\hline & Control group & 50 & 0.5 & I & 0 & 4 & \\
\hline \multirow[t]{2}{*}{ December } & Intervention group & 43 & 0.5 & 1.4 & 0 & 7 & 0.682 \\
\hline & Control group & 47 & 0.6 & 1.6 & 0 & 8 & \\
\hline \multirow[t]{2}{*}{ January } & Intervention group & 25 & 0.5 & 1.1 & 0 & 4 & 0.106 \\
\hline & Control group & 50 & 1.1 & 1.8 & 0 & 8 & \\
\hline \multirow[t]{2}{*}{ February } & Intervention group & 15 & 1.7 & 2.7 & 0 & 8 & 0.101 \\
\hline & Control group & 46 & 0.8 & 1.5 & 0 & 6 & \\
\hline \multirow[t]{2}{*}{ March } & Intervention group & 46 & 0.6 & 1.6 & 0 & 8 & 0.746 \\
\hline & Control group & 41 & 0.7 & 1.8 & 0 & 8 & \\
\hline
\end{tabular}

Abbreviations: SD, standard deviation; VAS, visual analog scale.

Table 2 Players with pain in the throwing shoulder, illustrated in the number of people and precantage. Mean pain intensity on VAS for these players are also shown

\begin{tabular}{|c|c|c|c|c|}
\hline Month & Group & $\mathbf{N}$ & $\begin{array}{l}\text { Number of people } \\
\text { in percentage }\end{array}$ & $\begin{array}{l}\text { Mean on VAS for } \\
\text { players reporting pain }\end{array}$ \\
\hline \multirow[t]{2}{*}{ September } & Intervention group & $21 / 52$ & 40.4 & 2 \\
\hline & Control group & $13 / 53$ & 24.5 & 2.8 \\
\hline \multirow[t]{2}{*}{ October } & Intervention group & $7 / 36$ & 19.4 & 1.6 \\
\hline & Control group & $13 / 53$ & 24.5 & 1.8 \\
\hline \multirow[t]{2}{*}{ November } & Intervention group & $11 / 44$ & 25 & 3.4 \\
\hline & Control group & $12 / 50$ & 24 & 2 \\
\hline \multirow[t]{2}{*}{ December } & Intervention group & $7 / 43$ & 16.3 & 2.9 \\
\hline & Control group & $10 / 47$ & 21.3 & 2.8 \\
\hline \multirow[t]{2}{*}{ January } & Intervention group & $5 / 25$ & 20 & 2.4 \\
\hline & Control group & $23 / 50$ & 46 & 2.4 \\
\hline \multirow[t]{2}{*}{ February } & Intervention group & $7 / 15$ & 43.7 & 3.7 \\
\hline & Control group & $16 / 46$ & 34.7 & 2.4 \\
\hline \multirow[t]{2}{*}{ March } & Intervention group & $8 / 46$ & 17.4 & 3.4 \\
\hline & Control group & ||$/ 4 \mid$ & 26.8 & 2.5 \\
\hline
\end{tabular}

Abbreviation: VAS, visual analog scale.

Table 3 A presentation of the score on Quick-DASH and the sport-specific part of the form, Quick-DASH-sport, in addition to the mean score, SD and $p$-value

\begin{tabular}{|c|c|c|c|c|c|c|c|c|c|}
\hline & $\mathbf{N}$ & Mean & Change & SD & $\mathbf{N}$ & Mean & Change & SD & $p$-value \\
\hline Quick-DASH baseline & 53 & 7.7 & & 7.2 & 53 & 6.4 & & 7.3 & 0.383 \\
\hline Quick-DASH posttest & 46 & 4.4 & -3.3 & 4.8 & 41 & 6.2 & -0.2 & 7.6 & 0.184 \\
\hline Quick-DASH-sport baseline & 53 & 5.1 & & 9.3 & 53 & 7.3 & & 15.5 & 0.370 \\
\hline Quick-DASH-sport posttest & 46 & 3.5 & -1.6 & 7.1 & 41 & 9.5 & +2.2 & 17.5 & $0.048^{*}$ \\
\hline
\end{tabular}

Note: $* p<0.05$

Abbreviations: SD, standard deviation; DASH, Disability of the Arm, Shoulder and Hand.

could reduce shoulder complaints among 16-year-old female team handball players. In summary, this study showed that a strength-training program had no effect on preventing shoulder pain among junior female team handball players. The mean pain intensity measured on VAS showed no significant difference in or between the groups at baseline or posttest. Young female team handball players do report pain in the throwing shoulder but grade the pain low on VAS. A significant difference was found between the groups on the sport-specific part of the quick-DASH form, but it did not fulfill the minimal demand to change and the players scored it low, something that indicates little functional problems when it comes to team handball. 
Table 4 A presentation of the physical tests performed at baseline and posttest, in addition to the mean, SD and $p$-value

\begin{tabular}{|c|c|c|c|c|c|c|c|c|c|}
\hline & \multicolumn{4}{|c|}{ Intervention group } & \multicolumn{5}{|c|}{ Control group } \\
\hline & $\mathbf{N}$ & Mean & Change & SD & $\mathbf{N}$ & Mean & Change & SD & $p$-value \\
\hline Push-ups baseline & 52 & 3.1 & & 3.8 & 53 & 2.3 & & 3.7 & 0.257 \\
\hline Push-ups posttest & 46 & 6.4 & $+3.3(106 \%)$ & 5.7 & 41 & 3.6 & $+\mathrm{I} .3(56 \%)$ & 3.5 & $0.008^{*}$ \\
\hline Throwing distance pretest & 52 & 22.4 & & 4.3 & 51 & 21.8 & & 4.0 & 0.472 \\
\hline Throwing distance posttest & 47 & 24.0 & $+1.6(7.1 \%)$ & 3.7 & 42 & 22.6 & $+0.8(3.7 \%)$ & 3.5 & 0.073 \\
\hline Internal rotation baseline & 51 & 131.2 & & 25.4 & 53 & 138.5 & & 19.9 & $0-102$ \\
\hline Internal rotation posttest & 47 & 143.6 & $+12.4(9.5 \%)$ & 18.4 & 42 & 139.7 & $+1.2(0.8 \%)$ & 19.9 & 0.344 \\
\hline External rotation baseline & 51 & 122.6 & & 17.0 & 53 & 123.3 & & 15.4 & 0.819 \\
\hline External rotation posttest & 47 & 132.0 & $+9.4(7.6 \%)$ & 19.7 & 42 & 129.1 & $+5.8(4.7 \%)$ & 13.4 & 0.413 \\
\hline
\end{tabular}

Note: ${ }^{*} p<0.05$.

Abbreviation: SD, standard deviation.

Table 5 Response rate throughout the season given in number of players $(n)$ and percentage for both themes

\begin{tabular}{llllll}
\hline Month & \multicolumn{2}{l}{$\begin{array}{l}\text { Intervention } \\
\text { group }(\mathbf{n}=\mathbf{5 3})\end{array}$} & & \multicolumn{2}{l}{$\begin{array}{l}\text { Control group } \\
(\mathbf{n}=\mathbf{5 3})\end{array}$} \\
\cline { 2 - 3 } & $\mathbf{n}$ & $\%$ & & $\mathbf{n}$ & $\%$ \\
\hline September & 52 & 98.1 & 53 & 100 \\
October & 36 & 67.9 & 53 & 100 \\
November & 44 & 83 & 50 & 94.3 \\
December & 43 & 81.1 & 47 & 88.7 \\
January & 25 & 47.1 & 50 & 94.3 \\
February & 15 & 28.3 & 46 & 86.8 \\
March & 46 & 86.8 & 41 & 77.4 \\
\hline
\end{tabular}

\section{Shoulder pain}

No significant difference in pain intensity measured on VAS "today" was found between the intervention group and the control group or within the groups. If everything above 0 on the VAS was accounted as pain, there was a tendency toward a decrease in players reporting pain throughout the season. The intervention group went from 21 players (40.4\%) that reported pain at baseline down to eight players $(17.4 \%)$ at posttest. In the control group, 13 players $(24.5 \%)$ reported pain at baseline, while 11 players $(26.8 \%)$ reported pain at posttest. These tendencies are opposite to previous assumptions that shoulder pain will be higher during the season compared to the start of the season, since the load and the stress of the shoulder are thought to increase throughout the season. ${ }^{29}$ Andersson, ${ }^{18}$ who also found a seasonal variance in shoulder problems, indicated that the load put on the shoulder throughout the season is not as vital for the prevalence of shoulder problems as previously thought.

If the prevalence of shoulder pain is added up for the intervention group and the control group, it shows that $32.3 \%(n=34)$ of the players reported shoulder pain at baseline, while $21.8 \%(n=19)$ reported it at posttest. A previous study done on young female handball players (32) reported similar prevalence numbers. Thirty-four percent of the 149 young, female handball players in the age 16 and 18 years reported shoulder pain in that study. Another study of 16 years old female handball players reported that $34 \%$ of the players in the intervention group and $23 \%$ of the players in the control group reported shoulder pain in the beginning of the season. ${ }^{15}$ Similar numbers are also found in a Danish study where $14 \%$ of the players reported pain now, while $33 \%$ reported pain previously. ${ }^{33}$ Since the study included both 16- and 18-year-old handball players of both sexes, it is not directly comparable.

A high prevalence of shoulder pain is also found in senior team handball. Thirty-six percent of the female elite players reported to have shoulder pain on the day of testing, while $58 \%$ reported previous or present shoulder pain (31). Among male handball players, $32 \%$ reported present shoulder pain, while $75 \%$ reported present or previous shoulder pain. ${ }^{18}$ This indicates that shoulder pain is common among both junior female handball players and senior handball players of both sex.

The mean pain intensity measured on VAS showed no significant difference in or between the groups at baseline or posttest. Both the intervention group and the control group reported pain under 1 on VAS at baseline and posttest. If we just look at the players who reported pain, the tendency was that the intervention group had less players reporting pain at posttest compared to baseline, but they reported more pain. The number of players with shoulder pain went from 13 to 11 players, while the mean pain intensity on VAS went from 2.8 to 2.5 .

A previous study on young female handball players reported a mean pain intensity of 5.2, a much higher number than found that in this study. ${ }^{30}$ The study included both $16-$ and 18-year-old players. Other studies on younger handball players have not reported pain intensity on VAS, and it is for 


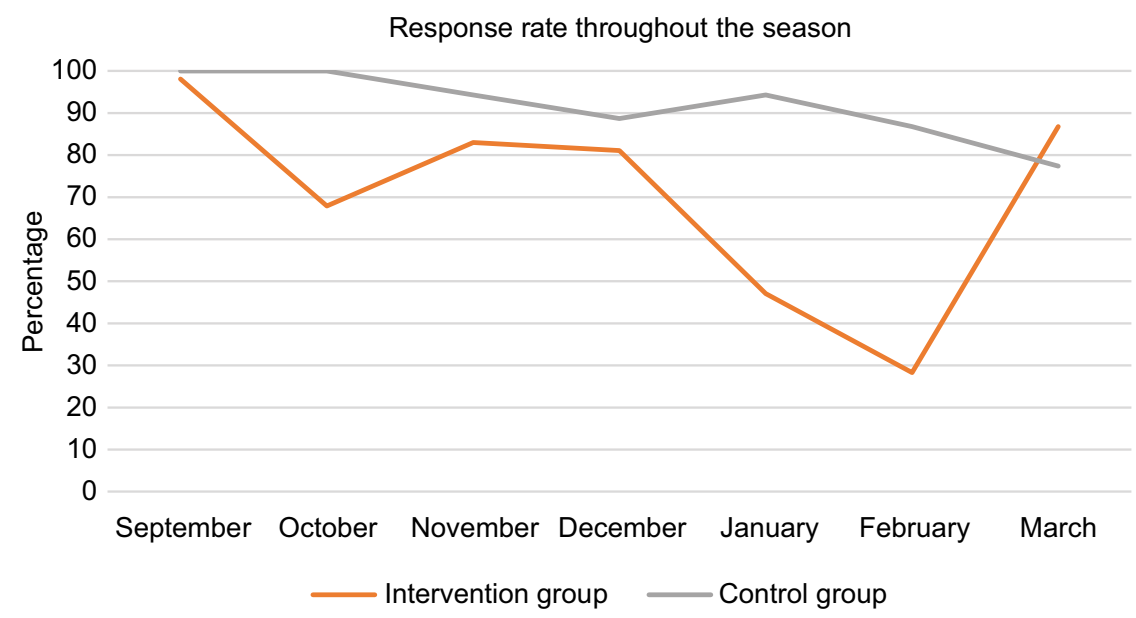

Figure 3 Response rate throughout the season given in percentage.

that reason not comparable. ${ }^{15,33}$ Female elite handball players also graded their shoulder pain higher on VAS, with the mean pain intensity on present shoulder pain measured to be 5.6 on VAS. ${ }^{29}$ A plausible reason for this could be that the pain increases with the higher age.

There could be a number of reasons why so many young female handball players reported to have pain in their throwing shoulder but rated it low on VAS. Pain is subjective, so what one person experiences as painful does not have to be painful for another person. Many factors can influence the experience of pain, and one of them can be the culture a person is a part of. ${ }^{34,35}$ Being part of an athletic environment can mean that having pain is part of the expectations a person has as a handball player. In a biopsychological aspect, one will act with the environment so that the pain signals can be modified by a non-pain-related factor, ${ }^{34}$ and because of that the athletes may have graded their pain low because feeling pain might be something that they both accept and expect.

A potential underestimation of pain intensity could also have appeared. An age of 16 years might lack a reference to both what pain is and when it comes to grading it. Another plausible explanation could be an uncertainty among the players on what is pain and aching in the muscles or delayed onset of muscle soreness (DOMS) ${ }^{18} \mathrm{~A}$ previous study showed that only $52 \%$ of the junior female handball players in the age group 16-18 reported that they had sought medical help for their shoulder pain. ${ }^{30}$ In comparison, $70 \%$ of the elite female handball players sought medical help. ${ }^{36}$ A possible explanation could be that older players have a more conscious relationship to pain, and that they have medical support, such as a doctor or physical therapist, within the team.

There is always a possibility that the selection is not representative for the study population. ${ }^{37} \mathrm{~A}$ randomized selection of the players was assured by randomizing and including both inclusion and exclusion criteria. Data on personal characteristics of the players were not collected (height, weight, amount of hours of weekly training and so on). This could further have assured that the selection was properly representative for the study population.

\section{Quick-DASH}

A significant difference $(p<0.05)$ was found between the groups on the sport-specific part of the Quick-DASH. While the intervention group decreased in score, the control group increased. Even though there was a significant difference, the difference did not achieve the minimal demand to change, which was set to $11.2 \%$. The score was also low to begin with, something that indicated little functional problems when it came to playing handball.

\section{Physical tests}

Except for the push-up test, there were no significant differences between the groups on the physical tests. The intervention group performed more push-ups on the posttest, and this increased from 3.1 to 6.4. A similar result was found in a previous study where push-up was one of the strength exercises to prevent shoulder pain among young handball players. ${ }^{15}$ In the study, players in the intervention group increased the number of push-ups even more on the posttest and improved the number of push-ups from 2.7 to 8.1 . Since the intervention group had been training push-ups throughout the season and a learning effect therefore had been taking place, ${ }^{38}$ the result was not so unexpected. Another possible element that could explain the increase in the number of push-ups could be maturation and the testing it-self, both of which could be a threat to the internal validity. ${ }^{37}$ 
A significant change was not found within or between the groups when it came to testing the strength with a dynamometer. A possible explanation why the groups did not increase their strength could be that they did not practice specific shoulder rotation exercises. The median could have been used as an alternative measure to avoid the result being inflsuenced by potential extreme values. ${ }^{28}$ The ratio number between the internal and external rotators was not significant at baseline or posttest.

There was no significant difference between or within the two groups when it came to throwing distance. It can be argued that testing the throwing distance still standing is not a natural throwing movement since handball players use both trunk rotation and the lower extremities to increase the speed of the throw. ${ }^{3}$ The thought was that by eliminating a possible co-movement, the shoulder was tested more specifically. A three-step throw, which is more used in handball, could have been an alternative. ${ }^{39}$

\section{Limitations}

A limitation of the study is the lack of compliance. All the coaches in the intervention group got a compliance form in the beginning of the season to fill in every time the training program was completed. None of the coaches handed over the form at the end of the season, so there was no compliance in this study. Low compliance is reported in several other preventative intervention studies, ${ }^{32,40,41}$ and therefore cannot be ruled out in this study either. A monthly collection of the compliance form might have made a difference, even though several preventative intervention studies have reported low compliance despite a frequent follow-up. ${ }^{40,41}$

Since the intervention group increased the number of push-ups on the posttest with over $100 \%$ (from 3.1 to 6.4), it could be argued that this is a good indication that the intervention group actually might have followed up the intervention routine. Another possible explanation of the increased number of push-ups could, of course, be maturation and the testing itself, both of which could be a threat to the inner validity. ${ }^{37}$

Another limitation of this study, and an element to take into consideration why so many players reported to have pain but graded it low, is the fact that the players filled in the questionnaires before handball training. It is possible that the answers would have been different if they had filled in after the training, since most handball players have pain related to throwing. ${ }^{36}$ As there were no clear recommendations in the literature, exercises for the intervention program were chosen among the spare recommendations that existed at the time being. Strength exercises were prioritized in regard to the injury mechanisms for shoulder injuries in overhead sports, and compliance was another important element that was taken into consideration when it came to choosing exercises. ${ }^{42}$ Since compliance is among the challenges in preventative intervention studies, ${ }^{32,40,41}$ an important focus in this study was to find exercises that were resource and time saving to complete.

The strength exercises were therefore chosen with the aim of achieving a best possible compliance. It was therefore a conscious choice to use exercises that were easy to do, and that did not demand any extra equipment, since the prevention effect is made up by the exercises, the dosage and compliance. The intervention groups were visited twice in the beginning of the season. More visits throughout the season could potentially have increased the compliance, but studies have reported low compliance despite a considerable effort to motivate the intervention groups. ${ }^{40,41}$

No information about the players' general characteristics, such as height and weight, amount of weekly handball training, and strength training, was gathered. Having this information could have assured that the selection was properly representative for the study population, so the lack of this information could therefore be seen as a limitation of this study.

\section{Clinical recommendations}

Future intervention studies with the goal of reducing shoulder pain among young female team handball players should implement recommendations based on new etiological studies. ${ }^{43} \mathrm{~A}$ better control of the intervention should be attempted, and an electrical response registration should be used.

\section{Conclusion}

A strength-training program had no effect on preventing shoulder pain among junior female team handball players. The mean pain intensity measured on VAS showed no significant difference in or between the groups at baseline or posttest. Young female team handball players do report pain in the throwing shoulder but grade the pain low on VAS. Both the intervention group and the control group reported pain under 1 on VAS at baseline and posttest. A significant difference was found between the groups on the sport-specific part of the quick-DASH form, but it did not fulfill the minimal demand to change and the players scored it low, something that indicates little functional problems when it comes to team handball. The intervention group performed significantly more push-ups on the posttest compared to the control group, and this increased from 3.1 to 6.4. Besides that, no significant differences were found between the groups. 


\section{Disclosure}

The authors report no conflicts of interest in this study.

\section{References}

1. Jørgensen U. Epidemiology of injuries in typical Scandinavian team sports. Br J Sports Med. 1984;18(2):59-63.

2. Norges Håndballforbund. Available from: https://www.handball.no/ regioner/nhf-sentralt/om-oss/organisasjon/nokkeltall/. Accessed April 15, 2016.

3. Kelly L, Terry GC. Team handball: shoulder injuries, rehabilitation, and training. Sports Med Arthrosc. 2001;9(2):115-123.

4. Jost B, Zumstein M, Pfirrmann CW, Zanetti M, Gerber C. MRI findings in throwing shoulders: abnormalities in professional handball players. Clin Orthop Relat Res. 2005;(434):130-137.

5. Langevoort G. Glenohumeral Instability. In: Langevoort G, editor. Sports Medicine and Handball. Switzerland; 1996;7:39-44. Cited by: Jost B, Zumstein M, Pfirrmann CW, Zanetti M, Gerber C. MRI findings in throwing shoulders: abnormalities in professional handball players. Clin Orthop Relat Res. 2005;(434):130-137.

6. Clarsen B, Bahr R, Andersson SH, Munk R, Myklebust G. Reduced glenohumeral rotation, external rotation weakness and scapular dyskinesis are risk factors for shoulder injuries among elite male handball players: a prospective cohort study. Br J Sports Med. 2014;48(17):1327-1333.

7. Kibler WB, Kuhn JE, Wilk K, et al. The disabled throwing shoulder: spectrum of pathology-10-year update. Arthroscopy. 2013;29(1):141-161.

8. McMullen J, Uhl TL. A kinetic chain approach for shoulder rehabilitation. J Athl Train. 2000;35(3):329-337.

9. Kibler WB, Press J, Sciascia A. The role of core stability in athletic function. Sports Med. 2006;36(3):189-198.

10. Wilk KE, Obma P, Simpson CD, Cain EL, Dugas JR, Andrews JR. Shoulder injuries in the overhead athlete. J Orthop Sports Phys Ther. 2009;39(2):38-54.

11. Wilk KE, Meister K, Andrews JR. Current concepts in the rehabilitation of the overhead throwing athlete. Am J Sports Med. 2002;30(1):136-151.

12. Seil R, Rupp S, Tempelhof S, Kohn D. Sports injuries in team handball. A one-year prospective study of sixteen men's senior teams of a superior nonprofessional level. Am J Sports Med. 1998;26(5):681-687.

13. Tovin BJ, Reiss JP. Shoulder. In: Kolt GS, Snyder-Mackler L, editors. Physical Therapies in Sport and Exercise. 2nd ed. Philadelphia: Elsevier; 2007:283-307.

14. Aune AK. Kroniske skulderlidelser. In: Bahr R, Mæhlum S, editors. Idrettsskader [Chronic shoulder disorders]. Oslo: Gazette; 2003:154171. Norwegian.

15. Østerås H, Sommervold M, Skjølberg A. Effect of a strength-training program for shoulder complaint prevention in female team handball athletes. A pilot study. J Sports Med Phys Fitness. 2015;55(7-8):761-767.

16. Almeida GP, Silveira PF, Rosseto NP, Barbosa G, Ejnisman B, Cohen M. Glenohumeral range of motion in handball players with and without throwing-related shoulder pain. J Shoulder Elbow Surg. 2013;22(5):602-607.

17. Edouard P, Degache F, Oullion R, Plessis JY, Gleizes-Cervera S, Calmels P. Shoulder strength imbalances as injury risk in handball. Int $J$ Sports Med. 2013;34(7):654-660.

18. Andersson SH. Nevromuskular kontroll som risikofaktor for skulderproblemer hos mannlige elitehåndballspillere-En prospektiv kohortstudie [Masterthesis] [Neuromuscular control as risk factor in male handball players; A prospective cohort study]. Oslo: Norges Idrettshøgskole; 2013. Norwegian.

19. Haldorsen B, Svege I, Roe Y, Bergland A. Reliability and validity of the Norwegian version of the Disabilities of the Arm, Shoulder and Hand questionnaire in patients with shoulder impingement syndrome. $B M C$ Musculoskelet Disord. 2014;15(1):78.

20. Mintken PE, Glynn P, Cleland JA. Psychometric properties of the shortened disabilities of the Arm, Shoulder, and Hand Questionnaire (QuickDASH) and Numeric Pain Rating Scale in patients with shoulder pain. J Shoulder Elbow Surg. 2009;18(6):920-926.
21. Aasheim T, Finsen V. The DASH and the QuickDASH instruments. Normative values in the general population in Norway. $J$ Hand Surg Eur Vol. 2014;39(2):140-144.

22. Huskisson EC. Measurement of pain. Lancet.1974;304(7889):1127-1131.

23. Ostelo RW, de Vet HC. Clinically important outcomes in low back pain. Best Pract Res Clin Rheumatol. 2005;19(4):593-607.

24. Byram IR, Bushnell BD, Dugger K, Charron K, Harrell FE Jr, Noonan TJ. Preseason shoulder strength measurements in professional baseball pitchers: identifying players at risk for injury. Am J Sports Med. 2010;38(7):1375-1382.

25. CoolsAM,DeWildeL,VanTongelA,CeyssensC,RyckewaertR,CambierDC. Measuring shoulder external and internal rotation strength and range of motion: comprehensive intra-rater and inter-rater reliability study of several testing protocols. J Shoulder Elbow Surg. 2014;23(10):1454-1461.

26. Johansson FR, Skillgate E, Lapauw ML, et al. Measuring eccentric strength of the shoulder external rotators using a handheld dynamometer: reliability and validity. J Athl Train. 2015;50(7):719-725.

27. Benestad HB, Laake P, eds. Forskningsmetode i medisin og biofag. Oslo: Gyldendal Akademisk; 2004. Norwegian.

28. Aalen O, Frigessi A, Moger TA, Scheel I, Skovlund E, Veierød MB. Statistiske metoder i medisin og helsefag [Research methods in medicine and biological sciences]. Oslo: Gyldendal Akademisk; 2006. Norwegian.

29. Myklebust G, Hasslan L, Bahr R, Steffen K. High prevalence of shoulder pain among elite Norwegian female handball players. Scand J Med Sci Sports. 2013;23(3):288-294.

30. Sommervold M, Østerås H. Forekomst av skuldersmerter blant junior jentespillere i håndball [Incidence of shoulder pain among junior girl players in handball]. Fysioterapeuten. 2011;7(11):18-23. Norwegian.

31. Bots ML, Evan GW, Riley WA, Grobbee DE. Carotid intima-media thickness measurements in intervention studies: design options, progression rates, and sample size considerations: a point of view. Stroke. 2003;34(12):2985-2994.

32. Kristoffersen EL. Forebygging av skuldersmerter hos håndballspillere. En klyngerandomisert kontrollert pilotstudie [Prevention of shoulder pain among handball players] [Master's thesis]. Oslo: Norges Idrettshøyskole; 2008. Norwegian.

33. Møller M, Myklebust G, Attermann J, Wedderkopp N, Sørensen H, Lind M. Shoulder pain problems in youth handball. Br J Sports Med. 2014; 48(7):643.

34. Østerås $\mathrm{H}$, Stensdotter AK. Medisinsk treningslcere [Medical exercise theory]. 2nd ed. Oslo: Gyldendal akademisk; 2011. Norwegian.

35. Lasch KE. Culture, pain, and culturally sensitive pain care. Pain Manag Nurs. 2000;1(3 Suppl 1):16-22.

36. Hasslan L. Forekomst av skuldersmerter hos kvinnelige norske elitehåndballspillere: en tverrsnittstudie [Incidence of shoulder pain in female Norwegian handball players; a cross-sectional study] [Master's thesis]. Oslo: Norges Idrettshøyskole; 2009. Norwegian.

37. Thomas JR, Nelson JK, Silverman SJ. Research Methods in Physical Activity. 5th ed. Champaign: Human Kinetics; 2005.

38. Portney LG, Watkins MP. Foundations of Clinical Research: Applications to Practice. 3rd ed. Upper Saddle River, NJ: Pearson Education; 2009.

39. Marques MC, van den Tillaar R, Vescovi JD, González-Badillo JJ. Relationship between throwing velocity, muscle power, and bar velocity during bench press in elite handball players. Int J Sports Physiol Perform. 2007;2(4):414-422.

40. Myklebust G, Engebretsen L, Braekken IH, Skjølberg A, Olsen OE, Bahr R. Prevention of anterior cruciate ligament injuries in female team handball players: a prospective intervention study over three seasons. Clin J Sport Med. 2003;13(2):71-78

41. Steffen K, Myklebust G, Olsen OE, Holme I, Bahr R. Preventing injuries in female youth football - a cluster-randomized controlled trial. Scan J Med Sci Sports. 2008;18(5):605-614.

42. Cramer JA, Roy A, Burrell A, et al. Medication compliance and persistence: terminology and definitions. Value Health. 2008;11(1):44-47.

43. Andersson SH, Bahr R, Clarsen B, Myklebust G. Preventing overuse shoulder injuries among throwing athletes: a cluster-randomised controlled trial in 660 elite handball players. Br J Sports Med. Epub 2016 Jun 16. 


\section{Publish your work in this journal}

The Open Access Journal of Sports Medicine is an international, peer-reviewed, open access journal publishing original research, reports, reviews and commentaries on all areas of sports medicine. The journal is included on PubMed. The manuscript management system is completely online and includes a very quick and fair

Submit your manuscript here: http://www.dovepress.com/open-access-journal-of-sports-medicine-journal

peer-review system. Visit http://www.dovepress.com/testimonials.php to read real quotes from published authors. 